\title{
Optical-Fiber Microsphere-Based Temperature Sensors with ZnO ALD Coating-Comparative Study
}

\author{
Paulina Listewnik $^{1, *(\mathbb{D})}$, Mikhael Bechelany ${ }^{2}\left(\mathbb{D}\right.$, Paweł Wierzba ${ }^{1}$ (D) and Małgorzata Szczerska $^{1, *(\mathbb{D})}$ \\ 1 Department of Metrology and Optoelectronics, Faculty of Electronics, Telecommunications and Informatics, \\ Gdańsk University of Technology, 11/12 Narutowicza Street, 80-233 Gdańsk, Poland; pwierzba@eti.pg.edu.pl \\ 2 Institut Europeén Des Membranes, IEM, UMR 5635, Univ of Montpellier, CNRS, ENSCM, CEDEX 5, \\ 34095 Montpellier, France; mikhael.bechelany@umontpellier.fr \\ * Correspondence: pauliste@student.pg.edu.pl (P.L.); malszcze@pg.edu.pl (M.S.)
}

check for updates

Citation: Listewnik, P.; Bechelany, M.; Wierzba, P.; Szczerska, M. Optical-Fiber Microsphere-Based Temperature Sensors with ZnO ALD Coating-Comparative Study. Sensors 2021, 21, 4982. https://doi.org/ $10.3390 / \mathrm{s} 21154982$

Academic Editors: Stefan Bosse, Alberto Vallan, Thomas B. Messervey, Francisco Falcone and Stefano Mariani

Received: 2 June 2021

Accepted: 20 July 2021

Published: 22 July 2021

Publisher's Note: MDPI stays neutral with regard to jurisdictional claims in published maps and institutional affiliations.

Copyright: (c) 2021 by the authors. Licensee MDPI, Basel, Switzerland. This article is an open access article distributed under the terms and conditions of the Creative Commons Attribution (CC BY) license (https:// creativecommons.org/licenses/by/ $4.0 /)$.

\begin{abstract}
This study presents the microsphere-based fiber-optic sensor with the ZnO Atomic Layer Deposition coating thickness of $100 \mathrm{~nm}$ and $200 \mathrm{~nm}$ for temperature measurements. Metrological properties of the sensor were investigated over the temperature range from $100{ }^{\circ} \mathrm{C}$ to $300{ }^{\circ} \mathrm{C}$, with a $10{ }^{\circ} \mathrm{C}$ step. The interferometric signal was used to monitor the integrity of the microsphere and its attachment to the connecting fiber. For the sensor with a $100 \mathrm{~nm}$ coating, a spectrum shift of the reflected signal and the optical power of the reflected signal were used to measure temperature, while only the optical power of the reflected signal was used in the sensor with a $200 \mathrm{~nm}$ coating. The $\mathrm{R}^{2}$ coefficient of the discussed sensors indicates a linear fit of over 0.99 to the obtained data. The sensitivity of the sensors, investigated in this study, equals $103.5 \mathrm{nW} /{ }^{\circ} \mathrm{C}$ and $19 \mathrm{pm} /{ }^{\circ} \mathrm{C}$ or $11.4 \mathrm{nW} /{ }^{\circ} \mathrm{C}$ for $\mathrm{ZnO}$ thickness of $200 \mathrm{~nm}$ and $100 \mathrm{~nm}$, respectively.
\end{abstract}

Keywords: temperature sensor; fiber-optic sensor; photonic sensor; atomic layer deposition; microsphere; temperature; $\mathrm{ZnO}$

\section{Introduction}

Fiber-optic sensors have been developed and improved upon for a few decades. Due to their versatility, they are used in numerous fields, in industry, science and medicine [1-4]. Because of their many advantages, such as chemical inertness or resistance to electromagnetic interference, they can often be utilized in places where electric sensors cannot be applied, e.g., in an explosive or combustible atmosphere, severe climatic conditions and hard to access places [5-8]. Optimization of measurement parameters plays a significant role in the development of the fiber-optic sensors. While planning measurements, the selection of the sensor is a crucial element, depending on the application and conditions in which they will be performed. There are many ways to tune metrological properties of fiber-optic sensors.

Probably the most common method is modification of the sensor's structure. A broad variety of sensing heads can be created thanks to advancements in technology and fabrication techniques-especially in fiber-optic fusion splicers and laser-splicing systems, femtosecond lasers and chemical etching [9-13] — that allow a multitude of fiber-optic structures. Many of them, including microdiscs, microrings, tapers, microresonators and microspheres, are coupled with a high coherent light source to generate resonance within the structure, on the basis of the Whispering Mode Gallery (WMG) phenomenon [14,15].

Another way to modify fiber-optic sensors is by addition of a coating on either the flat end-face of the fiber or on the surface of the structure. The coatings consist of a variety of materials, mostly $2 \mathrm{D}$, and they can be deposited in different forms. Based on their properties they are used for specific applications. For example, due to its structure, graphene oxide coating is ideal for humidity and refractive index measurements [16]. Single-walled carbon nanotubes (SWCNT) [17] are used for the detection of ammonia, 
ethanol and methanol vapor because of their interaction with the coating. The Pd-Au layer is used for hydrogen-concentration sensing [18].

The deposition method of the coating is an important issue while modifying parameters of fiber-optic sensors. Depending on the deposition technique, e.g., dip-coating method, Atomic Layer Deposition or magnetron sputtering, geometry, uniformity and conformity vary widely [19-24].

Based on the type of sensor, several parameters can be optimized, e.g., adjustable cavity length, structure modification [25-28] and modifying metrological properties such as resolution, precision, sensitivity and accuracy $[29,30]$. Many researchers contribute to determining the properties and parameters of various materials and structures [31,32].

This study investigates the performance of the microsphere-based fiber-optic temperature sensors with a $100 \mathrm{~nm}$ and $200 \mathrm{~nm} \mathrm{ZnO}$ ALD coating. By combining several methods of modification of the fiber-optic sensors, the complexity of the measurement system can be reduced and the number of adjustable parameters is increased. The $\mathrm{ZnO}$ sensor properties were investigated in the range of $100{ }^{\circ} \mathrm{C}$ to $300{ }^{\circ} \mathrm{C}$. In this temperature range, $\mathrm{ZnO}$ is well known for its chemical stability in a broad variety of gaseous and liquid environments. For this reason, $\mathrm{ZnO}$ is widely used for gas-sensor applications, for instance [33].

\section{Materials and Methods}

Measurements were performed using a sensor made of a standard single-mode telecommunication optical fiber (SMF-28, Thorlabs Inc., Newton, NJ, USA) with a microsphere structure produced at the end of the fiber, using a fiber-optic splicer (FSU975, Ericsson, Stockholm, Sweden). To obtain a microsphere with a diameter of $245 \mu \mathrm{m}$, splicing proceeded in a three-step pull. The fiber-optic splicer uses an electric arc to melt the fiber, while the pulling causes the formation of a microsphere. By varying splicing parameters, such as time of pull, electric arc current and fiber distance, the process can be controlled to achieve a highly repeatable structure. After the manufacturing of the microsphere, the $\mathrm{ZnO}$ coating was deposited on its surface by the Atomic Layer Deposition (ALD) method. ALD is a vapor phase deposition technique enabling the synthesis of ultrathin films with a sub-nanometer thickness control. A key benefit of ALD is high conformality of produced layers. In fact, ALD can be used to coat complex 3D substrates with a conformal and uniform layer of high-quality materials, a capability unique amongst thin film deposition techniques. Therefore, by using ALD, we were certain that $\mathrm{ZnO}$ would be uniformly and accurately grown on the microspheres inside the deposition chamber [34]. A custom-made ALD reactor was used for deposition of $\mathrm{ZnO}$ layers. ALD was performed using sequential exposures of Diethyl Zinc and $\mathrm{H}_{2} \mathrm{O}$, separated by a purge of nitrogen with a flow rate of $100 \mathrm{sccm}$. The deposition regime for $\mathrm{ZnO}$ consisted of a $0.1 \mathrm{~s}$ pulse of DEZ, $20 \mathrm{~s}$ of exposure to DEZ, $40 \mathrm{~s}$ of purge with argon followed by $2 \mathrm{~s}$ pulse of $\mathrm{H}_{2} \mathrm{O}, 30 \mathrm{~s}$ of exposure to $\mathrm{H}_{2} \mathrm{O}$ and finally $60 \mathrm{~s}$ purge with argon. $\mathrm{ZnO}$ thin films with a different number of cycles were deposited on the microsphere and on Si substrates, for reference purposes. The temperature during the process was fixed at $100^{\circ} \mathrm{C}[35,36]$. After the deposition process, the sensor was connected to an optical coupler by fusion splicing.

To assess the quality of the structure and the deposited ZnO ALD coating of $100 \mathrm{~nm}$ thickness, the microsphere was investigated under Scanning Electron Microscope (SEM, Phenom XL G2, Thermo Fisher Scientific, Waltham, MA, USA). An example image of the microsphere, recorded at 1000x magnification, is shown in Figure 1.

The structure presented in Figure 1 exhibits excellent roundness, and the presence of the $\mathrm{ZnO}$ coating is confirmed.

The metrological properties of the sensor were assessed by performing measurements. The utilized setup, which consists of a light source, an optical spectrum analyzer, the developed sensor and a temperature calibrator, is presented in Figure 2. 


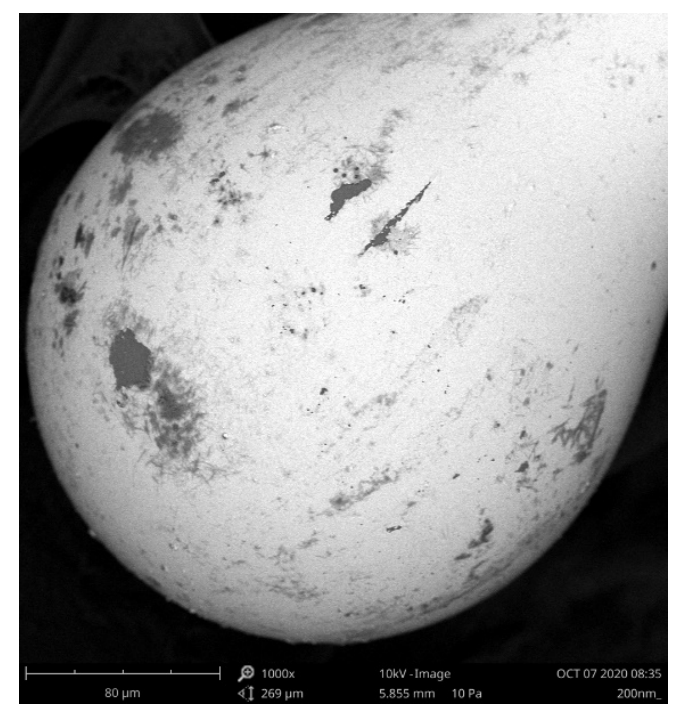

Figure 1. SEM image of the microsphere sensor with a $100 \mathrm{~nm}$ ZnO ALD coating. Magnification of $1000 \times$.

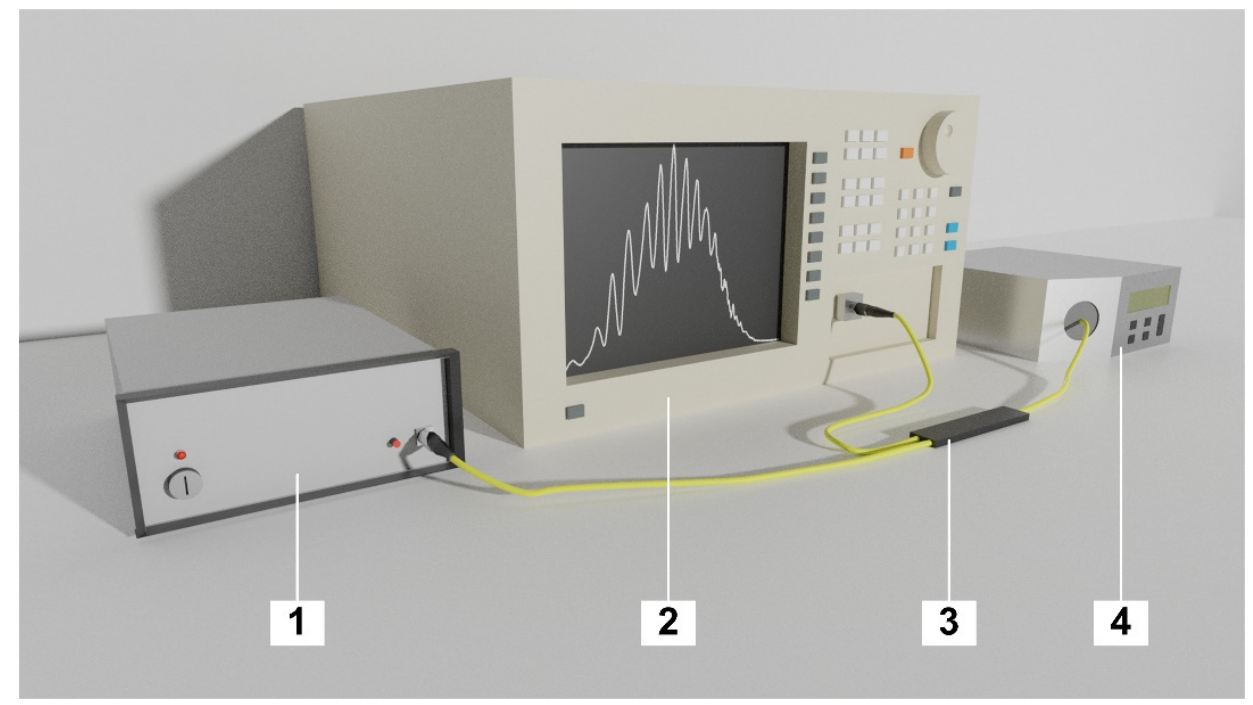

Figure 2. Experimental setup, where: 1-light source, 2-Optical Spectrum Analyzer, 3-Optical fiber coupler, 4-Temperature calibrator.

During the investigation, the sensor was placed in the temperature calibrator (ETC400A, Ametek, Berwyn, PA, USA). Temperature was increased from $100{ }^{\circ} \mathrm{C}$ to $300{ }^{\circ} \mathrm{C}$, with a $10{ }^{\circ} \mathrm{C}$ step. At each step the measurement was performed three minutes after the temperature had stabilized, allowing the sensor to adjust to altered conditions. The measurements were executed using a light source with a center wavelength of $1310 \mathrm{~nm} \pm 20 \mathrm{~nm}$ (SLD1310-18-W, FiberLabs Inc., Fujimino, Japan). The signal was propagated through a 2:1 $50 / 50 \%$ optical coupler (G657A, CELLCO, Kobylanka, Poland) to the sensor head coated with a $100 \mathrm{~nm} \mathrm{ZnO}$ ALD coating, where it was reflected, as shown in Figure 3. Due to differences in the refractive indices, the incident signal was reflected principally from the boundary between the core and the cladding glass, as well as from the boundary between the cladding glass and the $\mathrm{ZnO}$ layer. Both reflected waves were superposed and detected by the Optical Spectrum Analyzer (Ando AQ6319, Yokohama, Japan), in which they interfered, giving rise to a spectral interference pattern 


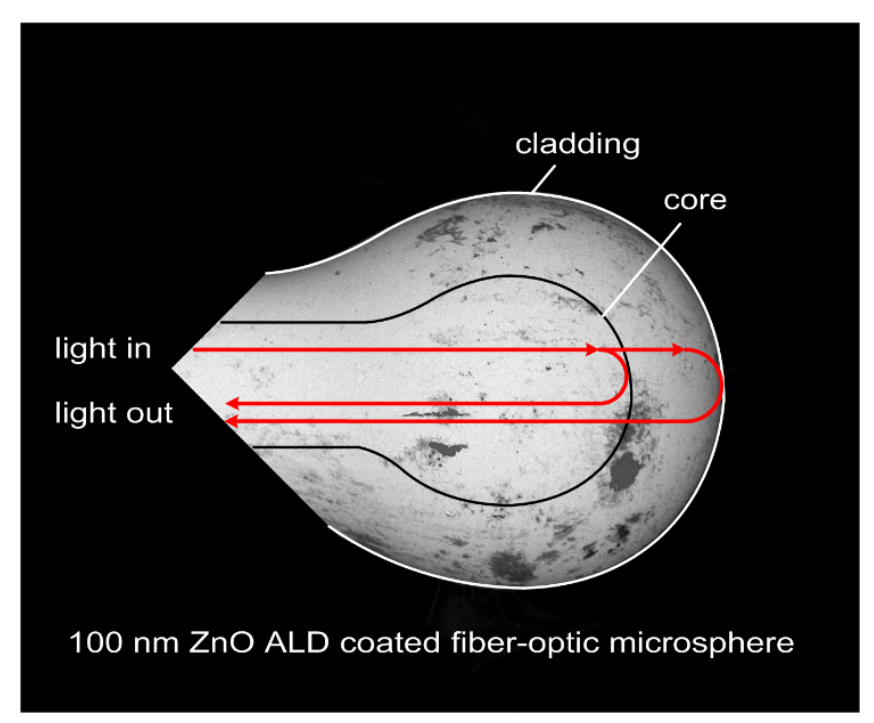

Figure 3. Principle of operation of a microsphere-based fiber-optic sensor.

The presence of the interference pattern confirms the integrity of the structure, ensuring that the sensor was not damaged. Depending on the position of the spectral peak of the signal, the temperature can be determined.

\section{Results and Discussion}

This section presents results that were acquired from the measurements performed with the setup shown above for the sensor with a $100 \mathrm{~nm} \mathrm{ZnO}$ ALD coating. The detailed results of an investigation of the sensor with $200 \mathrm{~nm}$ coating are presented elsewhere [37]. This section also describes the comparison of the data sets obtained for both sensors. The following comparison does not intend to determine which sensor or analysis type is better, but to present their metrological parameters.

Figure 4 shows normalized values of the measured signal response for the microspherebased sensor with a $100 \mathrm{~nm} \mathrm{ZnO}$ ALD coating at $100{ }^{\circ} \mathrm{C}$ and $300{ }^{\circ} \mathrm{C}$ to preserve the readability of the plot. By increasing the temperature, the spectral peak of the reflected signal shifts toward lower values of the wavelength. In addition, interference modulation of the spectrum visible in Figure 4 confirms the integrity of the sensor head structure, allowing its condition to be monitored in real time.

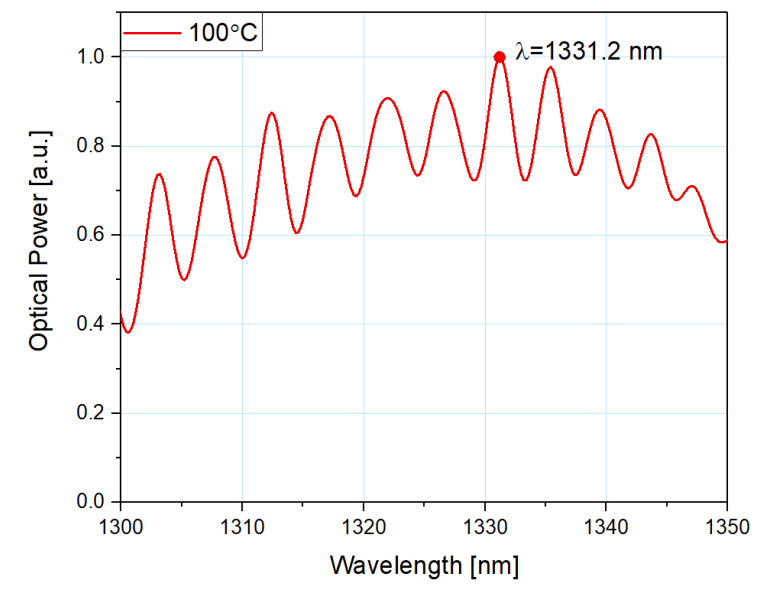

(a)

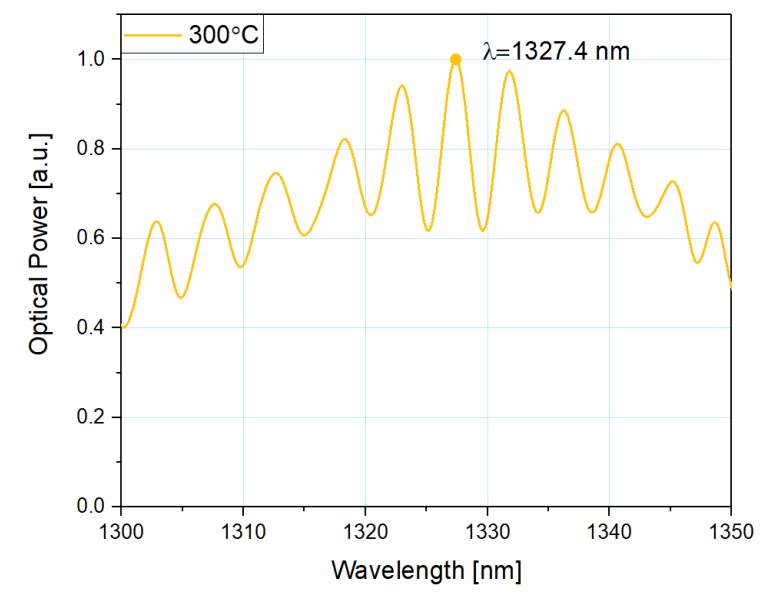

(b)

Figure 4. Normalized measured response of the reflected signal for the microsphere-based sensor with $100 \mathrm{~nm} \mathrm{ZnO}$ ALD coating at (a) $100{ }^{\circ} \mathrm{C}$ and (b) $300{ }^{\circ} \mathrm{C}$. 
The dependence of the peak wavelength position on the temperature is shown in Figure 5, along with the linear fit to the data. Coefficient $\mathrm{R}^{2}$ equals 0.991 , confirming good fit of the obtained data to the theoretical model. Furthermore, sensitivity of the microsphere-based sensor with a $100 \mathrm{~nm} \mathrm{ZnO}$ ALD coating was calculated to be $19 \mathrm{pm} /{ }^{\circ} \mathrm{C}$.

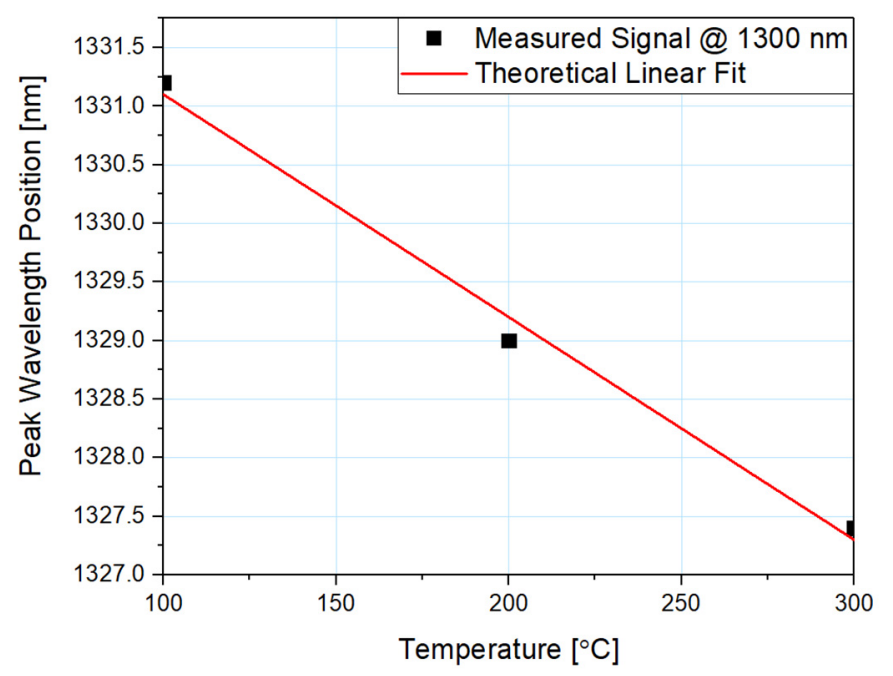

Figure 5. Dependence of the spectral shift of a reflected signal on the temperature.

The spectrum changes its peak wavelength position when the temperature is altered. As the temperature rises, the spectrum shifts by a constant value throughout the whole range of roughly $2 \mathrm{~nm}$ per $100{ }^{\circ} \mathrm{C}$. By following linear regression, it is possible to determine the measured temperature using the position of the peak of the reflected signal.

In addition to the peak wavelength shift, the sensor with a $100 \mathrm{~nm}$ ZnO ALD coating also retains the same property as the sensor with a $200 \mathrm{~nm}$ coating. The measured response of the reflected signal optical power for the sensor with a $100 \mathrm{~nm}$ coating is presented in Figure 6.

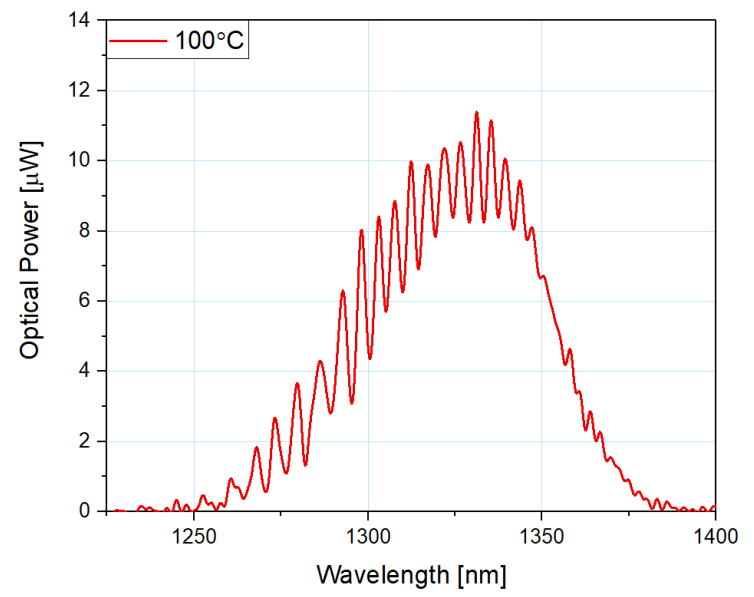

(a)

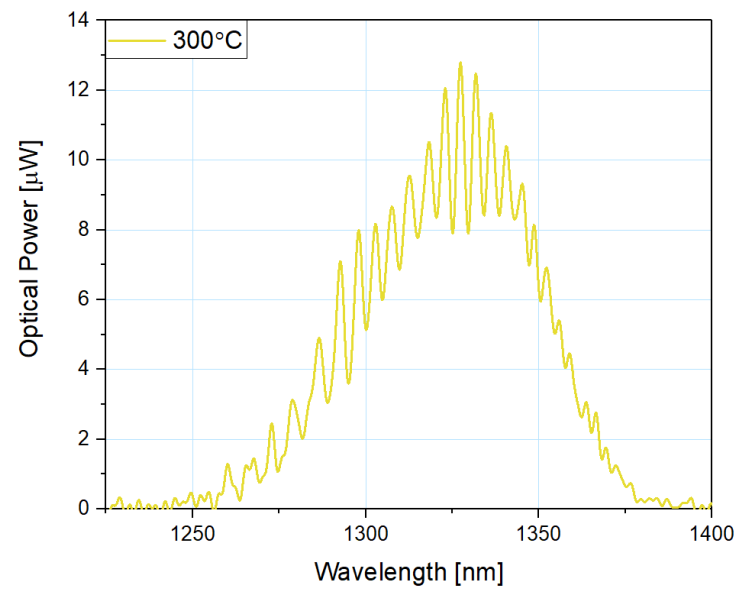

(b)

Figure 6. Measured response of the reflected signal optical power for the microsphere-based fiber-optic temperature sensor at: (a) $100{ }^{\circ} \mathrm{C}$, (b) $300^{\circ} \mathrm{C}$.

The peak optical power of the reflected signal increases when the temperature rises. The dependence of the reflected signal's optical power on the temperature is presented in Figure 7. 


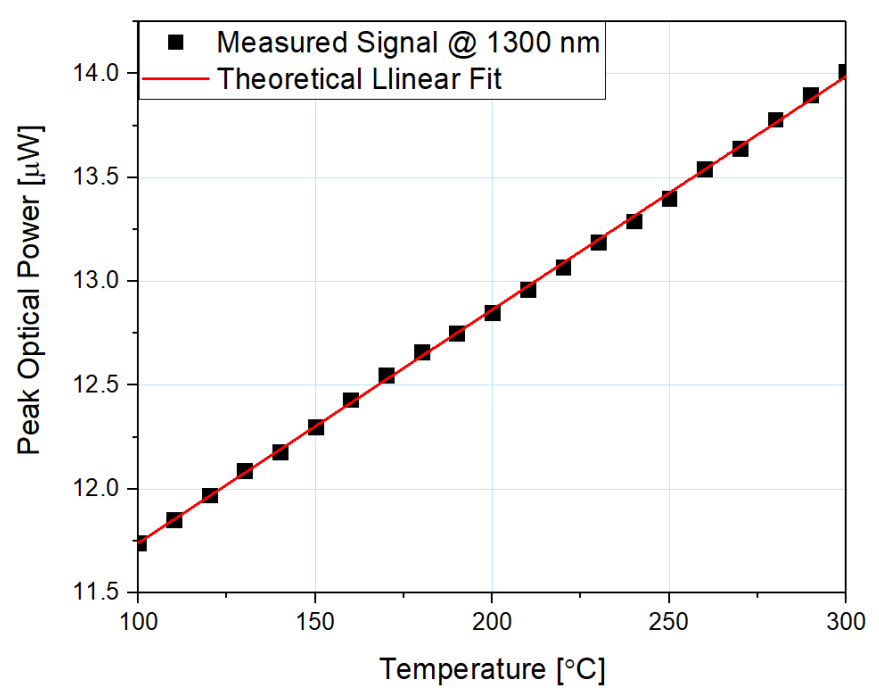

Figure 7. Reflected signal peak optical power dependence on the changing temperature and its theoretical linear fit, measured at a wavelength of $1300 \mathrm{~nm}$, using the microsphere-based sensor with $100 \mathrm{~nm} \mathrm{ZnO}$ ALD coating.

Based on the results presented in Figure 7, it can be concluded that the increase of the signal throughout the examined range is $16 \%$. The sensitivity of the microsphere-based sensor with $100 \mathrm{~nm} \mathrm{ZnO} \mathrm{ALD} \mathrm{coating} \mathrm{was} \mathrm{also} \mathrm{calculated,} \mathrm{and} \mathrm{it} \mathrm{equals} 11.35 \mathrm{nW} /{ }^{\circ} \mathrm{C}$. A linear fit to the experimental data was included in Figure 7 and the coefficient $R^{2}=0.999$ was calculated, confirming the good fit of obtained data to the theoretical model.

In addition, the values of linearity error, sensitivity error and approximation error were calculated. The data for the sensor with a $100 \mathrm{~nm}$ coating include both spectral and optical power analysis, because the device provides two ways of measurement.

Based on acquired data, the sensitivity of the sensors and sensitivity error, a deviation of this parameter from the one fitted from the theoretical zero-deviation slope, was calculated respectively from the Formulas (1) and (2):

$$
S=\frac{\Delta P}{\Delta T^{\prime}}
$$

where: $S$ —sensitivity of the sensor, $\Delta P$-optical power of the reflected signal, $\Delta T$-temperature range.

The sensitivity of the sensor with optical power analysis cannot be compared to the one with spectral shift. However, the parameters of both analysis methods are shown to provide metrological capabilities of the sensor. Depending on the nature of designed measurements, the required sensitivity can differ.

$$
u_{\text {sensitivity }}=\left(1-\frac{S_{\text {theor }}}{S}\right) * 100 \%
$$

where: $u_{\text {sensitivity }}$ - sensitivity error, $S_{\text {theor }}$ - theoretical fitting sensitivity.

As observed, in the spectral shift analysis the sensitivity error equals $0 \%$. The offset of the values is present, but the relative deviation takes the same values on both sides of the range. The sensitivity error in optical power analysis is close to $1 \%$.

The dependence of the changes occurring in the spectra on increasing temperature during measurements with each sensor is consistent with the linear characteristic, and the linear fit was included in the graphs. Therefore, the uncertainty of the obtained data to the theoretical model was calculated (3):

$$
u_{\text {linearity }}=\frac{\max \left|P-P_{\text {theor }}\right|}{\Delta I},
$$


where: $u_{\text {linearity }}$-linearity error, $P$-optical power of the reflected signal, $P_{\text {theor }}$ - theoretical fitting optical power.

The linearity error is almost 5 times lower while analyzing the data of optical power, in comparison to those analyzed in the spectral shift analysis.

The next calculated parameter was approximation error, which is the highest normalized difference between obtained data and its linear fit. The approximation error was calculated from the following Formula (4):

$$
\delta=\left|\frac{v_{M}-v_{R}}{v_{R}}\right| * 100 \%,
$$

where: $\delta$-approximation error, $v_{M}$-obtained data, $v_{R}$-linear fit.

For the approximation error, while in both instances it remains below $0.2 \%$, its value is 10 times lower $(0.02 \%)$ with spectral shift analysis. The parameters are presented in Table 1.

Table 1. Comparison between optical power and spectral shift analysis of parameters of the microsphere-based sensor with a $100 \mathrm{~nm}$ coating.

\begin{tabular}{|c|c|c|}
\hline Parameter & \multicolumn{2}{|c|}{100 nm Coating } \\
\hline Investigated range $\left[{ }^{\circ} \mathrm{C}\right]$ & \multicolumn{2}{|c|}{$100-300$} \\
\hline Characteristics & \multicolumn{2}{|c|}{ linear } \\
\hline Analysis type & spectral shift & optical power \\
\hline Sensitivity & $19 \mathrm{pm} /{ }^{\circ} \mathrm{C}$ & $11.35 \mathrm{nW} /{ }^{\circ} \mathrm{C}$ \\
\hline Sensitivity error $[\%]$ & 0 & 0.99 \\
\hline Theoretical sensitivity [\%] & $19 \mathrm{pm} /{ }^{\circ} \mathrm{C}$ & $11.24 \mathrm{nW} /{ }^{\circ} \mathrm{C}$ \\
\hline Linearity error $[\%]$ & 5.2 & 1.15 \\
\hline Approximation error [\%] & 0.02 & 0.2 \\
\hline $\mathrm{R}^{2}$ & 0.992 & 0.999 \\
\hline
\end{tabular}

Based on the $\mathrm{R}^{2}$ coefficient, it can be determined that the microsphere-based sensor with optical power analysis exhibits higher linearity.

Comparison of the normalized spectra of reflected signals from sensors with $200 \mathrm{~nm}$ and $100 \mathrm{~nm} \mathrm{ZnO}$ coating at $100{ }^{\circ} \mathrm{C}$ is presented in Figure 8. Normalization was performed to the highest value of optical power. It can be observed that the optical power of a sensor with a $200 \mathrm{~nm}$ coating is over 10 times higher than the optical power of a sensor with a $100 \mathrm{~nm}$ coating

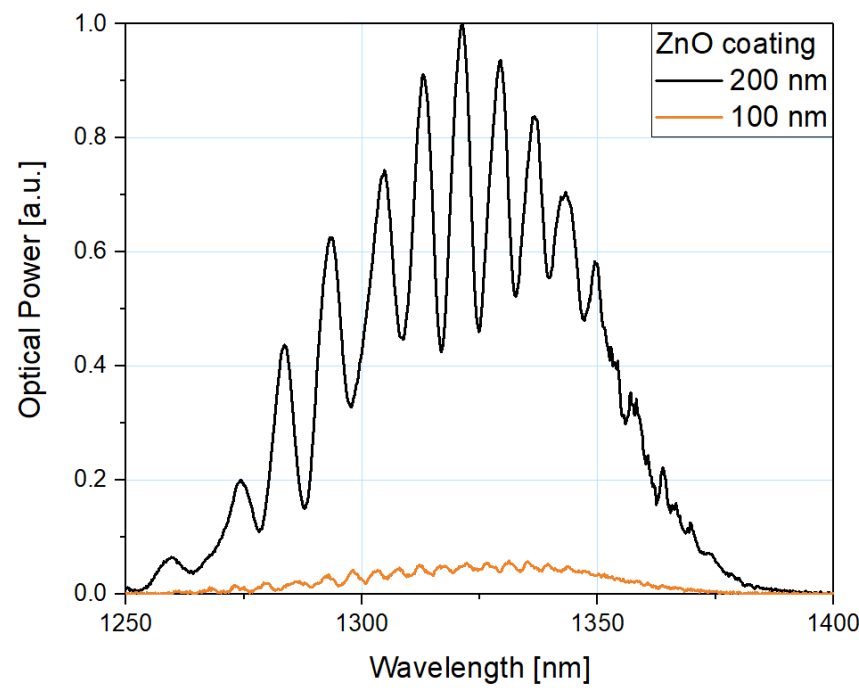

Figure 8. Normalized reflected spectra measured at $100{ }^{\circ} \mathrm{C}$ with microsphere-based sensors with a $200 \mathrm{~nm}$ (black line) and a $100 \mathrm{~nm}$ (orange line) ZnO ALD coating. 
Figure 9a shows the dependence of the peak optical power on temperature for microsphere fiber-optic sensors and their difference while using $200 \mathrm{~nm}$ and $100 \mathrm{~nm}$ ZnO ALD coating. Figure $9 \mathrm{~b}$ also shows their theoretical linear fit described by a linear function. Because the linear fit is a close match to the obtained data, by following linear regression it is possible to accurately predict metrological properties of the sensor at a temperature beyond the investigated range and to forecast the behavior of the sensor with any other thickness of a ZnO ALD coating. By considering the slope of the function, the sensitivity of the sensor can be further estimated, whereas by analyzing the $y$-intercept, the optical power level can be estimated.

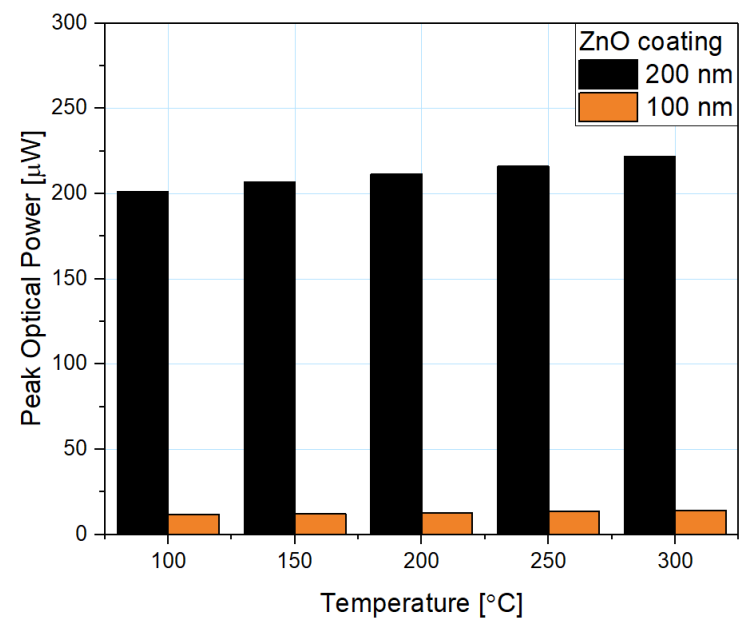

(a)

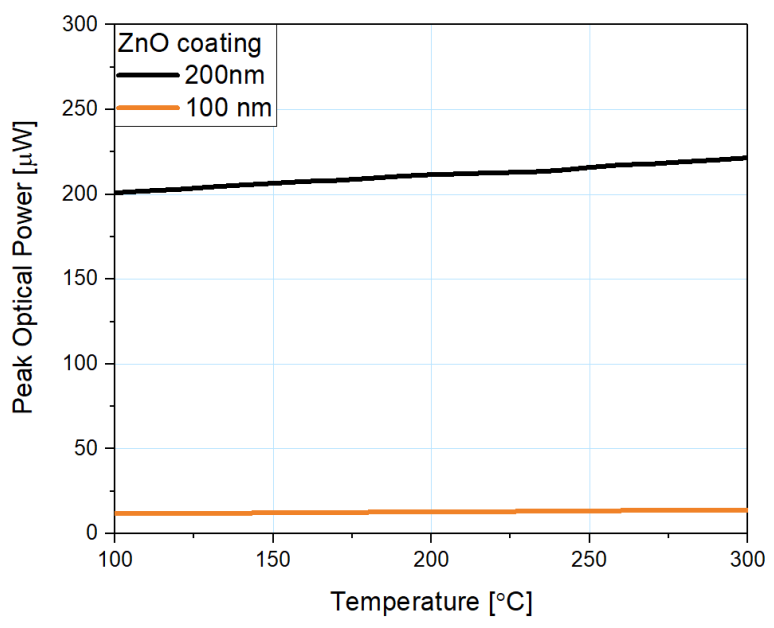

(b)

Figure 9. The dependency of the peak optical power on the temperature: (a) comparison of the obtained peak optical power of the reflected signal for each sensor, (b) obtained data and linear approximation.

In Table 2, a comparison of the metrological parameters for both sensors is presented.

Table 2. List of metrological parameters of the microsphere-based fiber-optic temperature sensorsoptical power analysis.

\begin{tabular}{lcc}
\hline Parameter & $\mathbf{1 0 0} \mathbf{~ n m}$ Coating & $\mathbf{2 0 0} \mathbf{~ n m ~ C o a t i n g ~}$ \\
\hline Investigated range $\left[{ }^{\circ} \mathrm{C}\right]$ & \multicolumn{3}{c}{$\begin{array}{c}\text { 100-300 } \\
\text { linear } \\
\text { Characteristics }\end{array}$} & optical power \\
Analysis type & 11.35 & 103.5 \\
Sensitivity [nW $\left./{ }^{\circ} \mathrm{C}\right]$ & 0.99 & 3.97 \\
Sensitivity error $[\%]$ & 11.24 & 99.39 \\
Theoretical sensitivity & 1.15 & 5 \\
{$\left[\mathrm{nW} /{ }^{\circ} \mathrm{C}\right]$} & 0.2 & 0.49 \\
Linearity error $[\%]$ & 0.999 & 0.995 \\
Approximation error $[\%]$ & & \\
$\mathrm{R}^{2}$ & & \\
\hline
\end{tabular}

As mentioned before, the measurement properties of the microsphere-based sensors with $\mathrm{ZnO}$ ALD coatings of $100 \mathrm{~nm}$ and $200 \mathrm{~nm}$ were investigated in the temperature range of $100{ }^{\circ} \mathrm{C}-300{ }^{\circ} \mathrm{C}$.

While the sensitivity error of the sensor with a $100 \mathrm{~nm}$ coating is, at most, $1 \%$, the sensor with a $200 \mathrm{~nm}$ coating exhibits a 3.97\% error. Throughout measurement planning, the sensitivity needed to accomplish the task must be considered. For investigations requiring lower sensitivity, the sensor with thinner ZnO ALD coating may still provide sufficient metrological parameters, while having a clear advantage in terms of time and cost of its production. As can be seen, the linearity error in terms of spectral analysis is almost 5 times lower for the sensor with a $100 \mathrm{~nm}$ coating. However, considering its linearity error 
by spectral analysis, it also deviates by $5 \%$. For both presented sensors, the approximation error was less than $0.5 \%$. By comparing $\mathrm{R}^{2}$ coefficients of both sensors, it is shown that the microsphere-based fiber-optic sensor with a $100 \mathrm{~nm}$ ZnO ALD coating indicates a closer match of the obtained data to the theoretical fit, and therefore its measured characteristic exhibits better linearity than that of the sensor with a $200 \mathrm{~nm}$ coating.

\section{Conclusions}

Microsphere-based sensors are good for long-term and remote measurement of temperature as integrity of the sensor head can be monitored, allowing any failure of the sensing head to be reliably detected. In this study, performance of a microsphere-based fiber-optic sensor for temperature measurements with a $100 \mathrm{~nm} \mathrm{ZnO}$ layer was investigated and compared with that of a sensor with a $200 \mathrm{~nm} \mathrm{ZnO}$ layer. The sensors exhibited a close match between measurement data and theoretical linear fit, which is confirmed by an $R^{2}$ coefficient exceeding 0.99 . The sensitivity of the sensor with a $100 \mathrm{~nm}$ coating equaled $0.019 \mathrm{~nm} /{ }^{\circ} \mathrm{C}$, while the sensitivity of the sensor with a $200 \mathrm{~nm}$ coating equaled $103.5 \mathrm{nW} /{ }^{\circ} \mathrm{C}$. Additionally, for the microsphere-based sensor with a $100 \mathrm{~nm} \mathrm{ZnO}$ ALD coating, changes of temperature were observed based on the optical power increase, which coincided with the rise of the temperature.

Author Contributions: Conceptualization, P.L. and M.S.; methodology, P.L. and M.S.; validation, P.L. and M.S.; formal analysis, P.L. and M.S.; investigation, P.L.; resources, M.B.; writing—original draft preparation, P.L. and M.B.; writing—review and editing, M.S. and P.W.; visualization, P.L.; supervision, M.S.; project administration, M.S.; funding acquisition, M.S. All authors have read and agreed to the published version of the manuscript.

Funding: This research was funded by the Polish National Agency for Academic Exchange-NAWA under a bilateral exchange of scientists between France and Poland PHC Polonium (PPN/BFR/2019/1/00005). Financial support of these studies from Gdańsk University of Technology by the 11/2020/IDUB/I.3/CC grant under the Curium Combating Coronavirus and by the 8/2020/IDUB/III.4.1/Tc grant under Technetium Talent Management Grants-EIRU programs is gratefully acknowledged. The authors acknowledge the financial support of the DS Programs of the Faculty of Electronics, Telecommunications and Informatics of the Gdańsk University of Technology.

Institutional Review Board Statement: Not applicable.

Informed Consent Statement: Not applicable.

Data Availability Statement: The data presented in this study are openly available in MOST Wiedzy repository at https:/ / doi.org/10.34808/3g4h-7p44 (accessed on 21 July 2021).

Conflicts of Interest: The authors declare no conflict of interest.

\section{References}

1. Xiong, F.B.; Sisler, D. Determination of Low-Level Water Content in Ethanol by Fiber-Optic Evanescent Absorption Sensor. Opt. Commun. 2010, 283, 1326-1330. [CrossRef]

2. Ramakrishnan, M.; Rajan, G.; Semenova, Y.; Farrell, G. Overview of Fiber Optic Sensor Technologies for Strain/Temperature Sensing Applications in Composite Materials. Sensors 2016, 16, 99. [CrossRef]

3. Karpienko, K.; Wróbel, M.S.; Jedrzejewska-Szczerska, M. Determination of Refractive Index Dispersion Using Fiber-Optic Low-Coherence Fabry-Perot Interferometer: Implementation and Validation. Opt. Eng. 2014, 53, 077103. [CrossRef]

4. Witt, J.; Narbonneau, F.; Schukar, M.; Krebber, K.; De Jonckheere, J.; Jeanne, M.; Kinet, D.; Paquet, B.; Depre, A.; D'Angelo, L.T.; et al. Medical Textiles With Embedded Fiber Optic Sensors for Monitoring of Respiratory Movement. IEEE Sens. J. 2012, 12, 246-254. [CrossRef]

5. Tripathi, S.M.; Bock, W.J.; Mikulic, P. A Wide-Range Temperature Immune Refractive-Index Sensor Using Concatenated LongPeriod-Fiber-Gratings. Sens. Actuators B Chem. 2017, 243, 1109-1114. [CrossRef]

6. Hromadka, J.; Mohd Hazlan, N.N.; Hernandez, F.U.; Correia, R.; Norris, A.; Morgan, S.P.; Korposh, S. Simultaneous in Situ Temperature and Relative Humidity Monitoring in Mechanical Ventilators Using an Array of Functionalised Optical Fibre Long Period Grating Sensors. Sens. Actuators B Chem. 2019, 286, 306-314. [CrossRef]

7. Li, M.; Dubaniewicz, T.; Dougherty, H.; Addis, J. Evaluation of Fiber Optic Methane Sensor Using a Smoke Chamber. Int. J. Min. Sci. Technol. 2018, 28, 969-974. [CrossRef] 
8. Kou, J.; Feng, J.; Ye, L.; Xu, F.; Lu, Y. Miniaturized Fiber Taper Reflective Interferometer for High Temperature Measurement. Opt. Express 2010, 18, 14245. [CrossRef]

9. Duan, D.-W.; Rao, Y.; Hou, Y.-S.; Zhu, T. Microbubble Based Fiber-Optic Fabry-Perot Interferometer Formed by Fusion Splicing Single-Mode Fibers for Strain Measurement. Appl. Opt. 2012, 51, 1033. [CrossRef]

10. Zhang, L.; Jiang, Y.; Jia, J.; Wang, P.; Wang, S.; Jiang, L. Fiber-Optic Micro Vibration Sensors Fabricated by a Femtosecond Laser. Opt. Lasers Eng. 2018, 110, 207-210. [CrossRef]

11. Zhang, Y.; Yuan, L.; Lan, X.; Kaur, A.; Huang, J.; Xiao, H. High-Temperature Fiber-Optic Fabry-Perot Interferometric Pressure Sensor Fabricated by Femtosecond Laser. Opt. Lett. 2013, 38, 4609. [CrossRef] [PubMed]

12. Cardona-Maya, Y.; Villar, I.D.; Socorro, A.B.; Corres, J.M.; Matias, I.R.; Botero-Cadavid, J.F. Wavelength and Phase Detection Based SMS Fiber Sensors Optimized With Etching and Nanodeposition. J. Lightwave Technol. 2017, 35, 3743-3749. [CrossRef]

13. Coelho, L.; de Almeida, J.M.M.M.; Santos, J.L.; Viegas, D. Fiber Optic Hydrogen Sensor Based on an Etched Bragg Grating Coated with Palladium. Appl. Opt. AO 2015, 54, 10342-10348. [CrossRef] [PubMed]

14. Liang, L.; Li, M.; Liu, N.; Sun, H.; Rong, Q.; Hu, M. A High-Sensitivity Optical Fiber Relative Humidity Sensor Based on Microsphere WGM Resonator. Opt. Fiber Technol. 2018, 45, 415-418. [CrossRef]

15. Ma, Q.; Rossmann, T.; Guo, Z. Whispering-Gallery Mode Silica Microsensors for Cryogenic to Room Temperature Measurement. Meas. Sci. Technol. 2010, 21, 025310. [CrossRef]

16. Dissanayake, K.P.W.; Wu, W.; Nguyen, H.; Sun, T.; Grattan, K.T.V. Graphene-Oxide-Coated Long-Period Grating-Based Fiber Optic Sensor for Relative Humidity and External Refractive Index. J. Lightwave Technol. 2018, 36, 1145-1151. [CrossRef]

17. Manivannan, S.; Saranya, A.M.; Renganathan, B.; Sastikumar, D.; Gobi, G.; Park, K.C. Single-Walled Carbon Nanotubes Wrapped Poly-Methyl Methacrylate Fiber Optic Sensor for Ammonia, Ethanol and Methanol Vapors at Room Temperature. Sens. Actuators B Chem. 2012, 171-172, 634-638. [CrossRef]

18. Westerwaal, R.J.; Rooijmans, J.S.A.; Leclercq, L.; Gheorghe, D.G.; Radeva, T.; Mooij, L.; Mak, T.; Polak, L.; Slaman, M.; Dam, B.; et al. Nanostructured Pd-Au Based Fiber Optic Sensors for Probing Hydrogen Concentrations in Gas Mixtures. Int. J. Hydrogen Energy 2013, 38, 4201-4212. [CrossRef]

19. Barranco, A.; Borras, A.; Gonzalez-Elipe, A.R.; Palmero, A. Perspectives on Oblique Angle Deposition of Thin Films: From Fundamentals to Devices. Prog. Mater. Sci. 2016, 76, 59-153. [CrossRef]

20. Brinker, C.J. Dip Coating. In Chemical Solution Deposition of Functional Oxide Thin Films; Schneller, T., Waser, R., Kosec, M., Payne, D., Eds.; Springer Vienna: Vienna, Austria, 2013; pp. 233-261. ISBN 978-3-211-99310-1.

21. Grosso, D. How to Exploit the Full Potential of the Dip-Coating Process to Better Control Film Formation. J. Mater. Chem. 2011, 21, 17033. [CrossRef]

22. Johnson, R.W.; Hultqvist, A.; Bent, S.F. A Brief Review of Atomic Layer Deposition: From Fundamentals to Applications. Mater Today 2014, 17, 236-246. [CrossRef]

23. George, S.M. Atomic Layer Deposition: An Overview. Chem. Rev. 2010, 110, 111-131. [CrossRef] [PubMed]

24. Sarakinos, K.; Alami, J.; Konstantinidis, S. High Power Pulsed Magnetron Sputtering: A Review on Scientific and Engineering State of the Art. Surf. Coat. Technol. 2010, 204, 1661-1684. [CrossRef]

25. Arif, M.D.F.H.; Ahmed, K.; Asaduzzaman, S.; Azad, M.D.A.K. Design and Optimization of Photonic Crystal Fiber for Liquid Sensing Applications. Photonic Sens. 2016, 6, 279-288. [CrossRef]

26. Van Newkirk, A.; Antonio-Lopez, E.; Salceda-Delgado, G.; Amezcua-Correa, R.; Schülzgen, A. Optimization of Multicore Fiber for High-Temperature Sensing. Opt. Lett. 2014, 39, 4812. [CrossRef]

27. Wierzba, P.; Jędrzejewska-Szczerska, M. Optimization of a Fabry-Perot Sensing Interferometer Design for an Optical Fiber Sensor of Hematocrit Level. Acta Phys. Pol. A 2013, 124, 586-588. [CrossRef]

28. Wang, Q.; Wei, W.; Guo, M.; Zhao, Y. Optimization of Cascaded Fiber Tapered Mach-Zehnder Interferometer and Refractive Index Sensing Technology. Sens. Actuators B Chem. 2016, 222, 159-165. [CrossRef]

29. Azad, S.; Sadeghi, E.; Parvizi, R.; Mazaheri, A.; Yousefi, M. Sensitivity Optimization of ZnO Clad-Modified Optical Fiber Humidity Sensor by Means of Tuning the Optical Fiber Waist Diameter. Opt. Laser Technol. 2017, 90, 96-101. [CrossRef]

30. Mishra, A.K.; Mishra, S.K.; Gupta, B.D. SPR Based Fiber Optic Sensor for Refractive Index Sensing with Enhanced Detection Accuracy and Figure of Merit in Visible Region. Opt. Commun. 2015, 344, 86-91. [CrossRef]

31. Song, N.; Cai, W.; Song, J.; Jin, J.; Wu, C. Structure Optimization of Small-Diameter Polarization-Maintaining Photonic Crystal Fiber for Mini Coil of Spaceborne Miniature Fiber-Optic Gyroscope. Appl. Opt. 2015, 54, 9831. [CrossRef]

32. Tu, M.H.; Sun, T.; Grattan, K.T.V. Optimization of Gold-Nanoparticle-Based Optical Fibre Surface Plasmon Resonance (SPR)-Based Sensors. Sens. Actuators B Chem. 2012, 164, 43-53. [CrossRef]

33. Weber, M.; Kim, J.-Y.; Lee, J.-H.; Kim, J.-H.; Iatsunskyi, I.; Coy, E.; Miele, P.; Bechelany, M.; Kim, S.S. Highly Efficient Hydrogen Sensors Based on Pd Nanoparticles Supported on Boron Nitride Coated ZnO Nanowires. J. Mater. Chem. A 2019, 7, 8107-8116. [CrossRef]

34. Graniel, O.; Weber, M.; Balme, S.; Miele, P.; Bechelany, M. Atomic Layer Deposition for Biosensing Applications. Biosens. Bioelectron. 2018, 122, 147-159. [CrossRef]

35. Viter, R.; Chaaya, A.A.; Iatsunskyi, I.; Nowaczyk, G.; Kovalevskis, K.; Erts, D.; Miele, P.; Smyntyna, V.; Bechelany, M. Tuning of ZnO 1D Nanostructures by Atomic Layer Deposition and Electrospinning for Optical Gas Sensor Applications. Nanotechnology 2015, 26, 105501. [CrossRef] [PubMed] 
36. Elias, J.; Utke, I.; Yoon, S.; Bechelany, M.; Weidenkaff, A.; Michler, J.; Philippe, L. Electrochemical Growth of ZnO Nanowires on Atomic Layer Deposition Coated Polystyrene Sphere Templates. Electrochim. Acta 2013, 110, 387-392. [CrossRef]

37. Listewnik, P.; Bechelany, M.; Jasinski, J.B.; Szczerska, M. ZnO ALD-Coated Microsphere-Based Sensors for Temperature Measurements. Sensors 2020, 20, 4689. [CrossRef] 